\title{
Inter- and intra-observer variability in the qualitative categorization of coronary angiograms
}

\author{
Jean-Paul R. Herrman, Aida Azar' ${ }^{1}$, Victor A.W.M. Umans, Eric Boersma, \\ Gerrit-Anne v. Es ${ }^{1} \&$ Patrick W. Serruys* \\ From the Department of Interventional Cardiology, Thoraxcenter, Erasmus University and ${ }^{1}$ the Department of \\ Epidemiology and Biostatistics, Cardialysis, Rotterdam, The Netherlands (* Corresponding author)
}

Accepted 1 November 1995

Key words: Coronary arteriography, lesion morphology, ACC/AHA classification, inter and intra observer variability, kappa

\begin{abstract}
The ABC classification of the American College of Cardiology and the American Heart Association is a commonly used categorization to estimate the risk and success of intracoronary intervention, as well as the probability of restenosis. To evaluate the reliability of qualitative angiogram readings, we randomly selected 200 films from single lesion angioplasty procedures. A repeated visual assessment ( $\geq 2$ months interval) by two independent observers resulted in kappa values of inter and intra-observer variability for the $\mathrm{ABC}$ lesion classification and for all separate items that compile it. Variability in assessment is expressed in percentage of total agreement, and in kappa value, which is a parameter of the agreement between two or more observations in excess of the chance agreement. Percentage of total agreement and kappa value was $67.8 \%$ and 0.33 respectively for the $\mathrm{ABC}$ classification, indicating a poor agreement. Probably this is due to the deficiency of strict definitions. Further investigation has to demonstrate whether improvement can be achieved using complete and detailed definitions without ambiguity, and consensus after panel assessment.
\end{abstract}

\section{Introduction}

In 1988 the task force of the American College of Cardiology and the American Heart Association (ACC/AHA) on assessment of diagnostic and therapeutic cardiovascular procedures presented guidelines for percutaneous transluminal coronary angioplasty (PTCA) [1], which were recently updated for current experience and technology [2]. They proposed a lesion classification, based on morphologic features that presumably influence the chance of successful outcome of coronary angioplasties and the risk of acute closure (Table 1). Lesions are categorized into type A (success $\geq 85 \%$, low risk of abrupt closure), type $B$ (success $60-85 \%$ and/or moderate risk of abrupt closure), and type $\mathrm{C}$ (success $\leq 60 \%$ and/or high risk of abrupt closure). In 1990, Ellis and colleagues modified the type B lesions into type B1 stenoses (only one adverse type B characteristic), and into type B2 stenoses (two or more adverse type B characteristics). This subdivision was based on multivariate analysis, indicating the cumulative weight of unfavourable lesion characteristics [3]. The lesion scoring system is in widespread clinical use nowadays in order to attempt risk stratification for PTCA patients and selection of the interventional devices available. It is well known that visual estimates of lesion severity and several lesion features are less reliable as e.g. quantitatively evaluated characteristics [4]. To measure the inter and intra observer variability of the qualitative items that compose the $\mathrm{ABC}$ lesion classification, and the TIMI flow grade [5] (Table 2), two experienced corelab readers (VU and $\mathrm{JH}$ ) performed a double independent and blinded reading of coronary angiograms. 
Table 1. Lesion specific characteristics of type A,B, and C lesions [1,2].

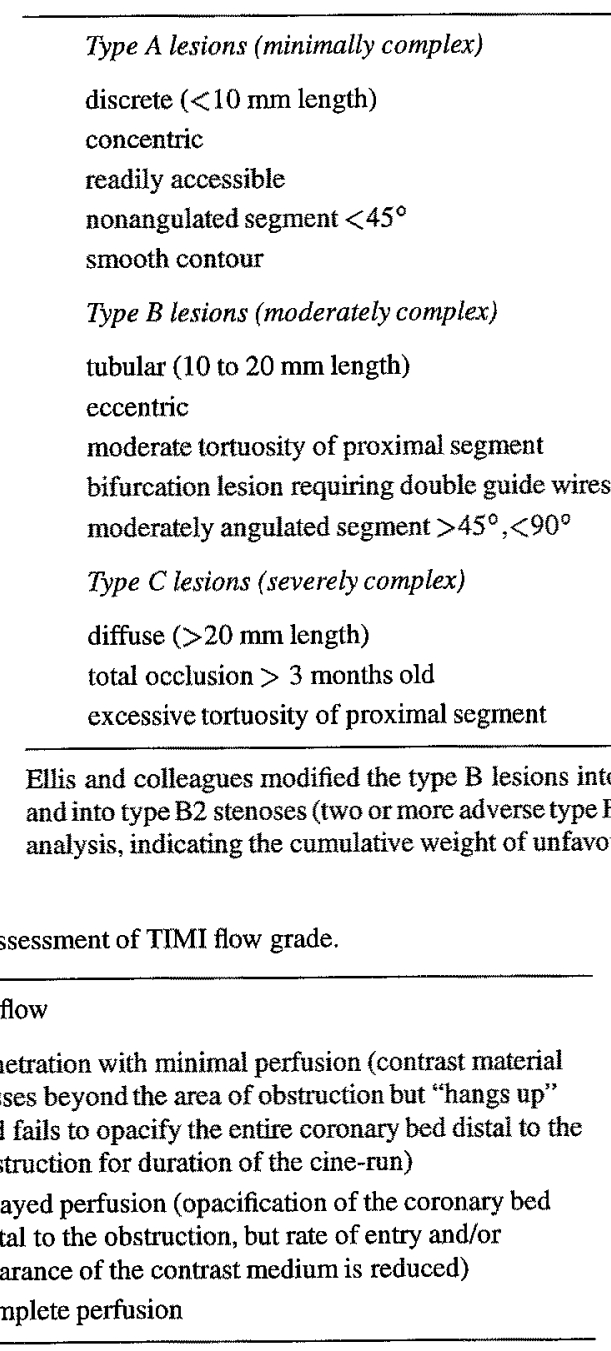

\begin{tabular}{|c|c|}
\hline I: & $\begin{array}{l}\text { penetration with minimal perfusion (contrast material } \\
\text { passes beyond the area of obstruction but "hangs up" } \\
\text { and fails to opacify the entire coronary bed distal to the } \\
\text { obstruction for duration of the cine-run) }\end{array}$ \\
\hline II: & $\begin{array}{l}\text { delayed perfusion (opacification of the coronary bed } \\
\text { distal to the obstruction, but rate of entry and/or } \\
\text { clearance of the contrast medium is reduced) }\end{array}$ \\
\hline III: & complete perfusion \\
\hline
\end{tabular}

\section{Methods}

\section{Patient identification} ber 1992 and may 1993, in patients with proven coronary artery disease in native arteries as shown by a unstable angina pectoris, according to the Braunwald

\section{Assessment of coronary angiograms} the pool of cinefilms available in the cardiovascu-
All cinefilms were made in the period between septemdiagnostic angiogram. All patients were treated for classification [6].

To assess the reliability of qualitative angiogram readings, we randomly selected 200 angiograms from

Table 2. Assessment of TIMI flow grade.

pool of cinefilms avalable in the cardiovascu- less than totally occlusive

little or no calcification

not ostial in location

no major branch involvement

absence of thrombus

moderate to heavy calcification

total occlusions $<3$ months old

some thrombus present

ostial in location

irregular contour

inability to protect major side branches

extremely angulated segment $>90^{\circ}$

degenerated vein grafts with friable lesions lar research laboratory Cardialysis. All the cinefilms recorded an intracoronary intervention of a single lesion. Those films were assessed independently by 2 observers. To assess intra-observer variability, the same set of cinefilms was analyzed at least 8 weeks later by the two observers who were blinded for the results of the first analysis. Except for concentricity, we used the definitions for morphologic characteristics from the original ACC/AHA task force project [1, 2]. We used the more differentiating Ambrose classification [7] to assess concentricity aspects and regularity of the lesion. Concentric and tandem lesions are smooth, like type I eccentric lesions. We defined multiple irregularities as concentric and irregular, and type II eccentric lesions as eccentric and irregular. We additionally scored TIMI flow. The assessors were blinded for clinical data, and therefore could not differentiate between TIMI flow grade 0 c.q. total occlusion existing less or longer than three months (ergo a type $B$ or type $\mathrm{C}$ characteristic). We added total occlusion to the four categories of the modified lesion classification.

\section{Statistical analysis}

Calculations revealed that a group size of 200 coronary cinefilms would be more than sufficient to achieve a reasonable to precise kappa-value (see Appendix). 
Table 3. Inter-observer variability between observers 1 and $2(\mathrm{~N}=199)$.

\begin{tabular}{lccccc}
\hline $\begin{array}{l}\text { Length of lesion } \\
\text { Observer } 1\end{array}$ & $\begin{array}{l}\text { Observer } 2 \\
<10 \mathrm{~mm}\end{array}$ & $10-20 \mathrm{~mm}$ & $>20 \mathrm{~mm}$ & N.A. & Total \\
\hline$<10 \mathrm{~mm}$ & 110 & 6 & 1 & 0 & 117 \\
$10-20 \mathrm{~mm}$ & 43 & 14 & 3 & 0 & 60 \\
$>20 \mathrm{~mm}$ & 3 & 5 & 0 & 2 & 10 \\
N.A. & 0 & 1 & 0 & 11 & 12 \\
Total & 156 & 26 & 4 & 13 & 199 \\
\hline
\end{tabular}

Kappa value $=0.35,95 \%$ confidence interval $0.25-0.35$, agreement is $67.8 \%$.

N.A. = Not applicable

\begin{tabular}{|c|c|c|c|c|c|c|c|c|c|}
\hline \multirow{2}{*}{$\begin{array}{l}\text { Ambrose lesion type } \\
\text { Observer } 1\end{array}$} & \multicolumn{9}{|c|}{ Observer 2} \\
\hline & Conc. & Ecc. IA & Ecc. IB & Ecc. IIA & Ecc.IIB & Mult. irreg. & Tandem & N.A. & Total \\
\hline Concentric & 48 & 1 & 1 & 2 & 0 & 3 & 1 & 0 & 56 \\
\hline Eccentric type & 2 & 3 & 1 & 1 & 7 & 0 & 0 & 0 & 14 \\
\hline IA Eccentric type IB & 44 & 14 & 34 & 1 & 3 & 3 & 0 & 1 & 100 \\
\hline Eccentric type IIA & 1 & 0 & 1 & 0 & 1 & 3 & 0 & 0 & 6 \\
\hline Eccentric type IIB & 2 & 1 & 1 & 0 & 0 & 0 & 0 & 0 & 4 \\
\hline Multiple irregularities & 1 & 1 & 0 & 0 & 0 & 1 & 0 & 0 & 3 \\
\hline Tandem lesion & 1 & 0 & 0 & 0 & 0 & 1 & 2 & 0 & 4 \\
\hline N.A. & 1 & 0 & 0 & 0 & 0 & 0 & 0 & 11 & 12 \\
\hline Total & 100 & 20 & 38 & 4 & 11 & 11 & 3 & 12 & 199 \\
\hline
\end{tabular}

Kappa value $=0.48,95 \%$ confidence interval $0.43-0.53$, agreement is $49.7 \%$.

Conc.$=$ concentric, Ecc. $=$ eccentric, Mult. irreg. $=$ multiple irregularities, Tandem $=$ tandem lesion, N.A. $=$ Not applicable

\begin{tabular}{llrrrr}
\hline TIMI flow grade & \multicolumn{2}{l}{ Observer 2 } & & \\
Observer 1 & TIMI 0 & TIMI I & TIMI II & TIMI III & Total \\
\hline TIMI 0 & 8 & 3 & 0 & 0 & 11 \\
TIMI I & 0 & 4 & 1 & 1 & 6 \\
TIMI II & 0 & 3 & 11 & 9 & 23 \\
TIMI III & 0 & 1 & 13 & 145 & 159 \\
Total & 8 & 11 & 25 & 155 & 199 \\
\hline
\end{tabular}

Kappa value $=0.57,95 \%$ confidence interval $0.45-0.68$, agreement is $84.4 \%$

\begin{tabular}{lrllr}
\hline Tortuosity & \multicolumn{2}{c}{ Observer 2 } & & \\
Observer 1 & No & Moderate & Severe & Total \\
\hline No & 196 & 1 & 0 & 197 \\
Moderate & 1 & 0 & 0 & 1 \\
Severe & 1 & 0 & 0 & 1 \\
Total & 198 & 1 & 0 & 199 \\
\hline
\end{tabular}

Kappa value $=1.00$, agreement is $98.5 \%$

\begin{tabular}{lrrr}
\hline $\begin{array}{l}\text { Branchpoint involved } \\
\text { in the stenosis }\end{array}$ & \multicolumn{2}{c}{ Observer 2} & \\
Observer 1 & No & Yes & Total \\
\hline No & 143 & 6 & 149 \\
Yes & 32 & 18 & 50 \\
Total & 175 & 24 & 199 \\
\hline
\end{tabular}

Kappa value $=0.39,95 \%$ confidence interval $0.26-0.52$, agreement is $80.9 \%$ 
Table 3. Continued.

\begin{tabular}{lrrr}
\hline $\begin{array}{l}\text { Relationship to coronary } \\
\text { artery bend } \\
\text { Observer } 1\end{array}$ & \multicolumn{3}{c}{ Observer 2} \\
\hline No & Yes & Total \\
Yes & 186 & 4 & 190 \\
Bad quality & 4 & 4 & 8 \\
Total & 1 & 0 & 1 \\
\hline
\end{tabular}

Kappa value $=0.48,95 \%$ confidence interval 0.22 0.74 , agreement is $95.5 \%$

\begin{tabular}{lrrr}
\hline Presence of thrombus & \multicolumn{3}{c}{ Observer 2} \\
Observer 1 & No & Yes & Total \\
\hline No & 190 & 3 & 193 \\
Yes & 2 & 4 & 6 \\
Total & 192 & 7 & 199 \\
\hline
\end{tabular}

Kappa value $=0.60,95 \%$ confidence interval $0.34-0.86$, agreement is $97.5 \%$

\begin{tabular}{lrrr}
\hline $\begin{array}{l}\text { Presence of calcium } \\
\text { Observer 1 }\end{array}$ & \multicolumn{3}{c}{ Observer 2 } \\
No & Yes & Total \\
\hline No & 164 & 12 & 176 \\
Yes & 8 & 14 & 22 \\
Bad quality & 1 & 0 & 1 \\
Total & 173 & 26 & 199 \\
\hline
\end{tabular}

Kappa value $=0.53,95 \%$ confidence interval $0.38-0.68$, agreement is $89.4 \%$

\begin{tabular}{lrrrrrrr}
\hline Lesion type & \multicolumn{1}{c}{ Observer 2} & & & \\
Observer 1 & A & B1 & B2 & C & T.O. & Bad quality & Total \\
\hline A & 20 & 2 & 0 & 0 & 0 & 0 & 22 \\
B1 & 28 & 39 & 6 & 2 & 0 & 0 & 75 \\
B2 & 15 & 34 & 28 & 3 & 0 & 0 & 80 \\
C & 1 & 3 & 4 & 0 & 0 & 2 & 10 \\
T.O. & 0 & 1 & 1 & 0 & 8 & 2 & 12 \\
Total & 64 & 79 & 39 & 5 & 8 & 4 & 199 \\
\hline
\end{tabular}

Kappa value based on A, B1, B2 and C classes $=0.29,95 \%$ confidence interval $0.21-0.37$, agreement is $47.7 \%$.

Kappa value based on $A, B$ and C classes $=0.33,95 \%$ confidence interval $0.25-0.41$, agreement is $67.8 \%$.

T.O $=$ totally occlusive coronary artery
The degree of agreement was measured as percentage of total agreement, and using the kappa statistics, which is a parameter of the agreement between two or more observations in excess of the chance agreement [8]. If there is perfect agreement, then kappa $=+1.00$ and in case of pure chance agreement, then kappa = 0.00 . It is usual to consider kappa values greater than 0.75 to represent excellent agreement beyond chance, and values below 0.40 to represent poor agreement beyond chance and to values between 0.40 and 0.75 to represent fair to good agreement beyond chance. Kappa value was calculated as (observed-expected)/ (1-expected).

Double data entry secured accuracy. BMDP was used as statistical software package.

\section{Results}

In the first assessment one film was not assessable, therefore a total of 199 films were analyzed. The interobserver variability between observer 1 and 2 (Table 3 ) showed poor agreement for $\mathrm{ABC}$ lesion classification $(\mathrm{k}=0.33)$ and the modified $(\mathrm{A}, \mathrm{B} 1, \mathrm{~B} 2, \mathrm{C})$ classification $(k=0.29)$, length of lesion $(k=0.35)$, and branch point involvement in stenosis $(k=0.39)$. Fair to good agreement was found for Ambrose classification $(\mathrm{k}=0.48)$, relationship to coronary artery bend $(\mathrm{k}=0.48)$, vessel calcification $(\mathrm{k}=0.53)$, TIMI flow grade $(k=0.57)$, and thrombus $(k=0.60)$. Perfect agreement was found for ostial lesion $(k=1.00)$ and tortuosity $(\mathrm{k}=1.00)$.

Percentage of total agreement was found lowest in Ambrose classification (49.7\%), and lesion length $(67.8 \%)$. The agreement on modified (A, B1, B2, C) $\mathrm{ABC}$ classification was only $47.7 \%$, and on the original tri-modal $\mathrm{ABC}$ score improved to $67.8 \%$. Kappa however raised only from 0.29 to 0.33 . Agreement for calcification and branch point involvement was reached in 89.4 and $80.9 \%$ of the cases. In all the other items the percentage of total agreement is over $90 \%$.

Both observers demonstrated excellent agreement in intra-observer variability for tortuosity, relationship to coronary artery bend and ostial localization. All other studied lesion characteristics showed fair to good agreement for intra-observer variability (Table 4). 
Table 4. Intra-observer variability for observer 1 and $2(\mathrm{~N}=197)$.

Each cell gives the number of observations for observer 1 (top) and observer 2 (bottom).

\begin{tabular}{lccccc}
\hline $\begin{array}{l}\text { Length of lesion } \\
\text { Observation 1 }\end{array}$ & $\begin{array}{l}\text { Observation } 2 \\
<10 \mathrm{~mm}\end{array}$ & $10-20 \mathrm{~mm}$ & $>20 \mathrm{~mm}$ & N.A. & Total \\
\hline$<10 \mathrm{~mm}$ & 92 & 23 & 0 & 0 & 115 \\
& 144 & 9 & 1 & 0 & 154 \\
$10-20 \mathrm{~mm}$ & 19 & 39 & 2 & 0 & 60 \\
& 9 & 13 & 3 & 1 & 26 \\
$>20 \mathrm{~mm}$ & 0 & 4 & 6 & 0 & 10 \\
N.A. & 1 & 0 & 3 & 12 & 4 \\
& 0 & 0 & 0 & 9 & 12 \\
Total & 2 & 1 & 1 & 12 & 197 \\
& 111 & 66 & 8 & 10 & 197 \\
\hline
\end{tabular}

Kappa value observer $1=0.57,95 \%$ confidence interval $0.47-0.67$, agreement is $75.6 \%$.

Kappa value observer $2=0.61,95 \%$ confidence interval $0.51-0.71$, agreement is $85.8 \%$.

N.A. $=$ Not applicable

\begin{tabular}{|c|c|c|c|c|c|c|c|c|c|}
\hline \multirow{2}{*}{$\begin{array}{l}\text { Ambrose lesion type } \\
\text { Observation } 1\end{array}$} & \multicolumn{9}{|c|}{ Observation 2} \\
\hline & Conc. & Ecc. IA & Ecc. IB & Ecc. IIA & Ecc.IIB & Mult. irreg. & Tandem & N.A. & Total \\
\hline \multirow[t]{2}{*}{ Concentric } & 37 & 3 & 16 & 0 & 0 & 0 & 0 & 0 & 56 \\
\hline & 91 & 1 & 6 & 0 & 0 & 0 & 0 & 1 & 99 \\
\hline \multirow[t]{2}{*}{ Eccentric type IA } & 0 & 7 & 6 & 1 & 0 & 0 & 0 & 0 & 14 \\
\hline & 2 & 11 & 4 & 2 & 0 & 0 & 0 & 0 & 19 \\
\hline \multirow[t]{2}{*}{ Eccentric type IB } & 8 & 7 & 84 & 0 & 0 & 0 & 0 & 0 & 99 \\
\hline & 9 & 5 & 22 & 1 & 0 & 0 & 1 & 0 & 38 \\
\hline \multirow[t]{2}{*}{ Eccentric type IIA } & 0 & 6 & 0 & 0 & 0 & 0 & 0 & 0 & 6 \\
\hline & 2 & 0 & 0 & 1 & 1 & 0 & 0 & 0 & 4 \\
\hline \multirow[t]{2}{*}{ Eccentric type IIB } & 0 & 3 & 0 & 0 & 0 & 0 & 0 & 0 & 3 \\
\hline & 2 & 4 & 1 & 2 & 1 & 1 & 0 & 0 & 11 \\
\hline \multirow[t]{2}{*}{ Multiple irregularities } & 1 & 0 & 0 & 0 & 0 & 1 & 1 & 0 & 3 \\
\hline & 0 & 1 & 0 & 0 & 0 & 10 & 0 & 0 & 11 \\
\hline \multirow[t]{2}{*}{ Tandem lesion } & 0 & 0 & 0 & 0 & 0 & 0 & 4 & 0 & 4. \\
\hline & 0 & 0 & 0 & 0 & 0 & 0 & 3 & 0 & 3 \\
\hline \multirow[t]{2}{*}{ N.A. } & 0 & 0 & 0 & 0 & 0 & 0 & 0 & 0 & 12 \\
\hline & 1 & 1 & 1 & 0 & 0 & 0 & 0 & 9 & 12 \\
\hline \multirow[t]{2}{*}{ Total } & 46 & 26 & 106 & 1 & 0 & 1 & 5 & 12 & 197 \\
\hline & 107 & 23 & 34 & 6 & 2 & 11 & 4 & 10 & 197 \\
\hline
\end{tabular}

Kappa value observer $1=0.61,95 \%$ confidence interval $0.53-0.69$, agreement is $67.5 \%$.

Kappa value observer $2=0.66,95 \%$ confidence interval $0.59-0.73$, agreement is $75.1 \%$.

Conc $=$ concentric, Ecc. $=$ eccentric, Mult. irreg. $=$ multiple irregularities, Tandem $=$ tandem lesion, N.A. $=$ Not applicable

\section{Discussion}

Kappa statistics are a well known method of evaluating agreement between observers. This method is most useful when observations are frequent and have a Gaussian distribution. However the limitation arises when observations are relatively rare or even exceptional. One single outlying observation can then dramatically affect the kappa values. Figure 1 illustrates the relationship between kappa value and the distribution of observations over the cells. It shows clearly that percent agreement can remain constantly high (98\%), 
Table 4. Continued.

\begin{tabular}{lccccc}
\hline TIMI flow grade & \multicolumn{2}{c}{ Observation 2} & & & \\
Observation 1 & TIMI 0 & TIMI I & TIMI II & TIMI III & Total \\
\hline TIMI 0 & 11 & 0 & 0 & 0 & 11 \\
\multirow{2}{*}{ TIMI I } & 7 & 1 & 0 & 0 & 8 \\
& 1 & 4 & 1 & 0 & 6 \\
TIMI II & 1 & 7 & 1 & 2 & 11 \\
\multirow{2}{*}{ TIMI III } & 0 & 0 & 9 & 13 & 22 \\
& 0 & 3 & 14 & 7 & 24 \\
Total & 0 & 0 & 3 & 155 & 158 \\
& 0 & 2 & 8 & 144 & 154 \\
& 12 & 4 & 13 & 168 & 197 \\
& 8 & 13 & 23 & 153 & 197 \\
\hline
\end{tabular}

\begin{tabular}{lrrr}
\hline $\begin{array}{l}\text { Branchpoint involved } \\
\text { in the stenosis }\end{array}$ & \multicolumn{2}{c}{ Observation 2} & \\
Observation 1 & No & Yes & Total \\
\hline No & 143 & 4 & 147 \\
& 163 & 10 & 173 \\
Yes & 22 & 28 & 50 \\
& 7 & 17 & 24 \\
Total & 165 & 32 & 197 \\
& 170 & 27 & 197
\end{tabular}

Kappa value observer $1=0.61,95 \%$ confidence interval $0.50-0.72$, agreement is $86.8 \%$.

Kappa value observer $2=0.62,95 \%$ confidence interval $0.47-0.77$, agreement is $91.4 \%$.

Kappa value observer $1=0.70,95 \%$ confidence interval $0.59-0.81$, agreement is $90.9 \%$.

Kappa value observer $2=0.66,95 \%$ confidence interval $0.56-0.76$, agreement is $87.3 \%$.

\begin{tabular}{lrrr}
\hline Ostial lesion & \multicolumn{3}{c}{ Observation 2 } \\
Observation 1 & No & Yes & Total \\
\hline No & 188 & 1 & 189 \\
\multirow{2}{*}{ Yes } & 197 & 0 & 197 \\
& 1 & 7 & 8 \\
Total & 0 & 0 & 0 \\
& 189 & 8 & 197 \\
& 197 & 0 & 197 \\
\hline
\end{tabular}

\begin{tabular}{lrrr}
\hline $\begin{array}{l}\text { Relationship to coronary } \\
\text { artery bend }\end{array}$ & \multicolumn{2}{c}{ Observation 2 } \\
Observation 1 & No & Yes & Total \\
\hline No & 188 & 0 & 188 \\
& 189 & 0 & 189 \\
Yes & 2 & 6 & 8 \\
& 3 & 5 & 8 \\
Bad quality & 1 & 0 & 1 \\
& 0 & 0 & 0 \\
Total & 191 & 6 & 197 \\
& 192 & 5 & 197 \\
\hline
\end{tabular}

Kappa value observer $1=0.87,95 \%$ confidence interval $0.72-1.02$, agreement is $99.0 \%$.

Kappa value observer $2=1.00$, agreement is $100.0 \%$.

Kappa value observer $1=0.85,95 \%$ confidence interval $0.69-1.01$, agreement is $98.5 \%$.

Kappa value observer $2=0.76,95 \%$ confidence interval $0.55-0.97$, agreement is $98.5 \%$.

\begin{tabular}{lrrr}
\hline \multirow{2}{*}{$\begin{array}{l}\text { Presence of thrombus } \\
\text { Observation 1 }\end{array}$} & \multicolumn{3}{c}{ Observation 2 } \\
\hline No & No & Yes & Total \\
\multirow{2}{*}{ Yes } & 190 & 1 & 191 \\
& 187 & 3 & 190 \\
\multirow{2}{*}{ Total } & 2 & 4 & 6 \\
& 2 & 5 & 7 \\
& 192 & 5 & 197 \\
& 189 & 8 & 197 \\
\hline
\end{tabular}

Kappa value observer $1=0.72,95 \%$ confidence interval $0.46-0.98$, agreement is $98.5 \%$.

Kappa value observer $2=0.65,95 \%$ confidence interval $0.42-0.85$, agreement is $97.5 \%$. 
Table 4. Continued.

\begin{tabular}{lrrr}
\hline Presence of calcium & \multicolumn{3}{c}{ Observation 2} \\
Observation 1 & No & Yes & Total \\
\hline No & 172 & 2 & 174 \\
& 162 & 9 & 171 \\
Yes & 14 & 8 & 22 \\
& 13 & 13 & 26 \\
Bad quality & 1 & 0 & 1 \\
& 0 & 0 & 0 \\
Total & 187 & 10 & 197 \\
& 175 & 22 & 197 \\
\hline
\end{tabular}

Kappa value observer $1=0.46,95 \%$ confidence interval 0.28-0.64, agreement is $91.4 \%$.

Kappa value observer $2=0.48,95 \%$ confidence interval $0.59-0.73$, agreement is $88.8 \%$.

\begin{tabular}{|c|c|c|c|c|c|c|c|}
\hline \multirow{2}{*}{$\begin{array}{l}\text { Lesion type } \\
\text { Observation } 1\end{array}$} & \multicolumn{3}{|c|}{ Observation 2} & \multirow[b]{2}{*}{$\mathrm{C}$} & \multirow[b]{2}{*}{ T.O. } & \multirow[b]{2}{*}{$\begin{array}{l}\text { Bad } \\
\text { quality }\end{array}$} & \multirow[b]{2}{*}{ Total } \\
\hline & A & $\mathrm{B} 1$ & B2 & & & & \\
\hline \multirow[t]{2}{*}{ A } & 11 & 10 & 1 & 0 & 0 & 0 & 22 \\
\hline & 47 & 16 & 0 & 0 & 0 & 0 & 63 \\
\hline \multirow[t]{2}{*}{$\mathrm{B} 1$} & 11 & 42 & 20 & 1 & 0 & 0 & 74 \\
\hline & 13 & 54 & 8 & 2 & 0 & 1 & 78 \\
\hline \multirow[t]{2}{*}{ B2 } & 1 & 19 & 58 & 1 & 0 & 0 & 79 \\
\hline & 4 & 12 & 21 & 1 & 1 & 0 & 39 \\
\hline \multirow[t]{2}{*}{$\mathrm{C}$} & 0 & 3 & 1 & 6 & 0 & 0 & 10 \\
\hline & 1 & 0 & 0 & 4 & 0 & 0 & 5 \\
\hline \multirow[t]{2}{*}{ T.O. } & 0 & 0 & 0 & 0 & 12 & 0 & 12 \\
\hline & 0 & 0 & 0 & 0 & 7 & 1 & 8 \\
\hline \multirow[t]{2}{*}{ Bad quality } & 0 & 0 & 0 & 0 & 0 & 0 & 0 \\
\hline & 0 & 2 & 1 & 1 & 0 & 0 & 4 \\
\hline \multirow[t]{2}{*}{ Total } & 23 & 74 & 80 & 8 & 12 & 0 & 197 \\
\hline & 65 & 84 & 30 & 8 & 8 & 2 & 197 \\
\hline
\end{tabular}

Kappa value based on A, B1, B2 and C classes observer $1=0.49$, $95 \%$ confidence interval $0.40-0.57$, agreement is $65.5 \%$.

Kappa value based on A, B1, B2 and C classes observer $2=0.55$, $95 \%$ confidence interval $0.47-0.63$, agreement is $67.5 \%$.

Kappa value based on A, B and C classes observer $1=0.61,95 \%$ confidence interval $0.54-0.68$, agreement is $85.3 \%$.

Kappa value based on $A, B$ and $C$ classes observer $2=0.59,95 \%$ confidence interval $0.52-0.66$, agreement is $77.7 \%$.

$\mathrm{T} . \mathrm{O}=$ totally occlusive coronary artery

while kappa value ranges from -0.010 to 0.96 . The graph also depicts the possible abrupt change in kappa value when the majority of observations is concentrated in only one cell. Kappa value can change from -0.010 to 0.490 when one observation is differently positioned over the cells (Figure 1).
It is well known that visual estimates of lesion characteristics are less accurate in comparison to quantitatively derived parameters. Several variability and quality control studies have been conducted. Beauman and Vogel [9] compared visual estimations of lesion severity to quantitative analyses of percent diameter stenosis of coronary and phantom obstructions. Quantitatively assessed coronary arteries comprising a 50\% diameter stenosis, and $50 \%$ phantom stenoses recordings were visually scored in ranges from 15 to 80 percent, and 30 to 95 , percent respectively. Determination of the reference diameter showed that only $41 \%$ of the estimations were within $10 \%$ of the limits of the quantitatively derived diameter.

Another study [10] in 50 lesions reports the inter observer agreement of $73 \%$ for stenosis length (defined as the length of that portion of the stenosis that had a $\geq 30 \%$ reduction in luminal diameter using the adjacent normal vessel diameter as a "yardstick" or unit) and $64 \%$ for lesion eccentricity (defined as asymmetrically positioning in one or more views), resulting in kappa values of respectively 0.38 and 0.25 .

A report from our corelab [11] from 1990 reported the discordance in interobserver measurements in 151 lesions of $21 \%$ for lesion eccentricity ( $24 \%$ in our study), $29 \%$ for branch point involvement ( $18 \%$ in our study), $14 \%$ for location in a bend $(3.5 \%), 2 \%$ for presence of thrombus $(2.5 \%), 10 \%$ for presence of calcification ( $10 \%$ ), and $25 \%$ for the lesion type according to the ACC/AHA classification (32\%).

A recently presented study in 403 coronary lesions [12] demonstrated an excellent agreement for type $C$ lesions $(\mathrm{k}=0.85)$. Good agreement was shown for TIMI flow ( $\mathrm{k}=0.73), \mathrm{ABC}$ classification $(\mathrm{k}=0.48)$, angulation and side branch $(\mathrm{k}=0.48$ and 0.40 respectively). Poor achievement was reached in eccentricity, tortuosity, lesion calcification, and in the distinction of discrete, diffuse and tubular lesion length.

Mild discrepancies between the two assessors can be explained by insufficient quality in image acquisition, when e.g. overlap or foreshortening hampers assessment. Especially very proximal lesions in the left anterior descending artery are sometimes very difficult to explore visually, and are therefore subject of discordant descriptions.

Another source of incongruous assessment can be the experience of the angiographist. In this study one of the two MD's is interventional cardiologist (VU), while the other is a permanent assessor in the core lab of Cardialysis ( $\mathrm{JH})$. 


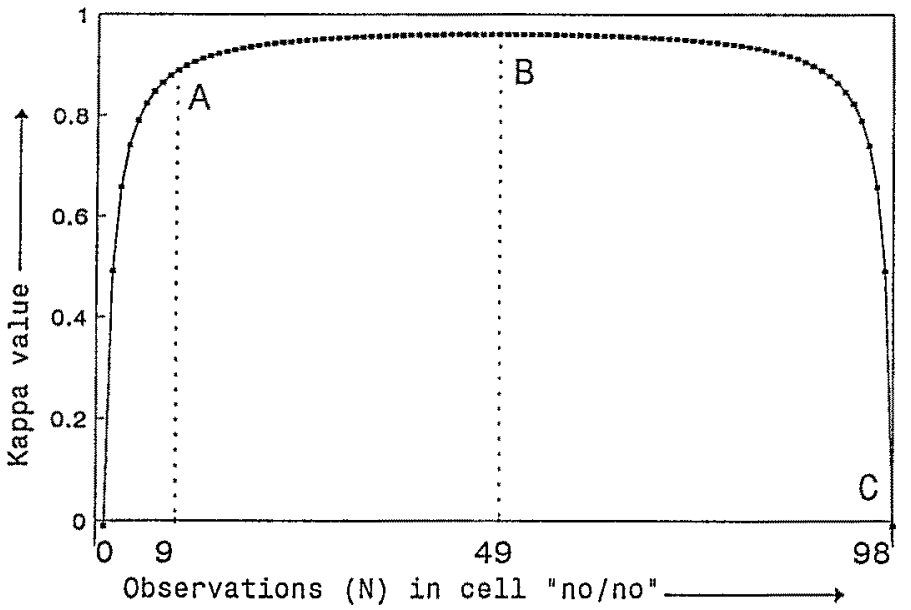

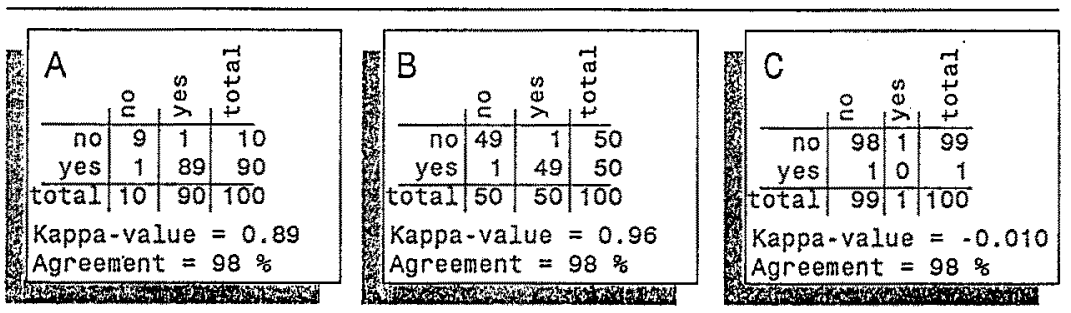

Figure 1. The graph plots the number of observations in the "no/no" cell on the X-axis against the kappa-value on the Y-axis, and illustrates the dependency of the kappa value to the distribution of the readings. In this example agreement between two observers is kept constant at a level of $98 \%$. The smaller boxes give the exact number of observations at three points in the graph, on which the kappa value and agreement are based.

An issue of essential relevance which contributes to the poor agreement within and between investigators is a clear description of the definitions of items to be assessed. The original and updated combined AHA/ACC [1,2] paper mentions the individual items on which the $\mathrm{ABC}$ classification is based, without detailed delineation of these elements. Many dissimilar definitions are in use throughout the literature. Although basically comparable, they differ in details, and cause discrepancies in cinefilm readings. Length of lesion e.g. can be interpreted e.g. as the length of plaque, related to the pre-defined size of the catheter on the image. An adjusted definition is the length where the stenosis $\geq 70 \%$ of the lumen diameter, or $\geq 50 \%$, or $\geq 30 \%$. This can then be expressed in absolute diameters or in terms of normal lumen diameter ratio [10]. Lesion length can also be defined as the calliper measurement of the distance from the proximal to the distal shoulder of the lesion in the projection that best elongated the stenosis. Cut-off points were chosen as $<10$ and $>20 \mathrm{~mm}$ [3]. We propose to use the definitions as listed in Table 5. They leave a minimum of space for different explanation and interpretation.
Panel assessment gives a substantial improvement in inter and intra observer agreement [9]. It is clear that the weighted sum of several simultaneous observations eliminates the most extreme disagreements, where the isolated assessor can develop his own interpretation and thus deviate from the original definitions.

Serial observations as in pre-readings, with knowledge of the results of the first observer's judgement may result in higher kappa-values for qualitatively assessed lesion characteristics. The mechanism of improved agreement in case of pre-reading however differs from improved agreement following panel assessment. In serial readings, the first judgement is merely dominant and respected by the second reviewer, who tends to compliance, implicating an improved outcome.

\section{Conclusions}

The data demonstrate a substantial discordance of agreement between two observers and also a partial lack of reproducibility of the results. These findings may be attributed to, among others: quality of data acquisition on film; experience of angiography asses- 
Table 5. List of proposed definitions to be used for qualitative assessment of coronary angiograms.

Symmetry: Lesions are judged for their symmetry depending on their appearance in any of multiple projections. Eccentric lesions are asymmetrically positioned in one or more views.

Categories: Concentric, Eccentric.

Roughness: The stenosis was judged to be rough if its luminal edge was irregular, or had a sawtooth component [3].

Categories: Discrete/smooth, Irregular contour.

Length of lesion: Estimation of the length of that portion of the stenosis that has a $\geq 50 \%$ reduction in luminal diameter. A contrast empty catheter tip is used for "visual calibration".

Categories: $<10 \mathrm{~mm}, 10-20 \mathrm{~mm},>20 \mathrm{~mm}, \mathrm{~N}$.A.

TIMI flow grade: [5]

0 : no flow,

I: penetration with minimal perfusion (contrast material passes beyond the area of obstruction but "hangs up" and fails to opacify the entire coronary bed distal to the obstruction for duration of the cine-run)

II: delayed perfusion (opacification of the coronary bed distal to the obstruction, but rate of entry and/or clearance of the contrast medium is reduced)

III: complete perfusion

Occlusion: Total obstruction without anterograde flow TIMI 0 . The distal vessel may or may not be filled by through retrograde or anterograde collateral (bridging) flow [13].

Categories: No total occlusion, Total occlusion.

A branch point is considered present if any part of the lesion $>30 \%$ narrowed is adjacent to a branch vessel that has a diameter of $25 \%$ or more of the diameter of the vessel being scored [3].

Categories: Branch point involved, Branch point not involved.

Bifurcation stenosis: The stenosis was recorded as a bifurcation stenosis if a branch vessel of medium or large size originated within the stenosis and iof the side branch was completely surrounded by significant stenostic portions of the lesion to be dilated [3].

Ostial lesion: When it involved the origin of the proximal LAD, LCX or RCA. When "ostial" and "bifurcation" occurred together they were counted as only one ACC/AHA class B characteristic [3].

Categories: Ostial, Not ostial located.

A bend point is considered present if in any angiographic projection orthogonal to the lesion, any part of the lesion is located in a portion of the vessel that has $a \geq 45$ degrees angulation at end diastole. CASS Registry [10] and ACC/AHA classification [1,2] Categories: Not located in a bend point, Mild bending, ( bend point $>45,<90$ degrees), Severe bending (bend point $>90$ degrees).

Calcifications are present if fixed radiopaque densities having the appearence of calcification are noted in any projection in the area of the stenosis to be dilated.

Categories: None, Little calcification, Heavy calcification.

Intra coronary thrombus is defined as presence of intraluminal non calcified central filling defect or lucency surrounded by contrast material seen in multiple projections, or persistence of contrast material within the lumen, or a visible embolization of intraluminal material downstream [14].

Categories: Absent, Present.

Tortuosity: Stenoses distal to two bends are in general scored as moderately tortuous, and those distal to three or more bends were considered to be associated with excessive tortuosity.

Categories: No tortuosity, Moderately tortuosity, Excessive tortuosity.

Tandem lesions were defined as adjacent separate lesions, more than three lumen diameters apart. This lesion does not include multiple separated lesions in different portions of the same vessel.

Categories: Tandem lesion, No tandem lesion.

sors; and mainly lack of strict definitions. Further investigation, preferably by panel assessment might be performed, only after agreement upon complete and detailed definitions for each angiographic variable.
Besides, if we want to estimate procedural success rates and the risk for procedural complications we have to debate operator experience and clinical variables. 


\section{References}

1. Ryan TJ, Faxon DP, Gunnar RM, Kennedy JW, King SB III, Loop FD, Peterson KL, Reeves TJ, Williams DO, Winters WL Jr. Guidelines for percutaneous transluminal coronary angioplasty: a report of the American College of Cardiology/American Heart Association Task Force on assessment of diagnostic and therapeutic cardiovascular procedures (subcommittee on percutaneous transluminal coronary angioplasty). $\mathrm{J}$ Am Coll Cardiol 1988; 12: 529-45 and Circulation 1988; 78 : 486-502

2. Ryan TJ, Bauman WB, Kennedy JW, Kereiakes DJ, King SB, McCallister BD, Smith SC jr, Ullyot DJ. Guidelines for percutaneous transluminal coronary angioplasty: A report of the American College of Cardiology/American Heart Association Task Force on assessment of diagnostic and therapeutic cardiovascular procedures (committee on percutaneous transluminal coronary angioplasty). J Am Coll Cardiol 1993; 22(7): 203354 and Circulation 1993; 88(6): 2987-3007.

3. Ellis SG, Vandormael MG, Cowley MJ, DiSciascio G, Deligonul U, Topol EJ, Bulle TM and the multivessel angioplasty prognosis study group. Coronary morphologic and clinical determinants of procedural outcome with angioplasty for multivessel coronary disease. Circ 1990; 82: 1193-1202

4. Bertrand ME, Lablanche JM, Bauters C, Leroy F, Mac Fadden E. Discordant results of visual and quantitative estimates of stenosis severity before and after coronary angioplasty. Cath and Cardiovasc Diagn 1993; 28: 1-6

5. The TIMI study group. The Thrombolysis In Myocardial Infarction (TIMI) trial: phase I findings. N Engl J Med 1985; 312: 932-936

6. Braunwald E. Unstable angina pectoris. A classification. Circulation 1989;80:410

7. Ambrose JA, Winters SL, Arora RR, Haft J, Goldstein J, Rentrop KP, Gorlin R, Fuster V. Coronary angiographic morphology in myocardial infarction: a link between the pathogenesis of unstable angina and myocardial infarction. Joum American Coll Cardiol 1985; 6(6): 1233-1238
8. Fleiss JH. Statistical methods for rates and proportions. 2nd ed. John Wiley \& Sons Inc. 1981: 212-236

9. Beauman GJ, Vogel RA. Accuracy of individual and panel visual interpretations of coronary arteriograms: implications for clinical decision making. Journ Am Coll Cardiol 1990; 16(1): 108-113

10. Ellis S, Alderman EL, Cain K, Wright A, Bourassa M, Fisher $\mathrm{L}$, and the participants of the coronary artery surgery study (CASS). Morphology of left anterior descending coronary territory lesions as a predictor of anterior myocardial infarction: a CASS registry study. Journ Am Coll Cardiol 1989; 13(7): 1481-91

11. Hermans WRM, Foley DP, Rensing BJ, Rutsch W, Heyndrickx GR, Danchin N, Mast G, Hanet C, Lablanche JM, Rafflenbeul W, Uebis R, Balcon R, de Feyter PJ, Serruys PW, on behalf of the Carport and Mercator Study Groups. Usefulness of quantitative and qualitative angiographic lesion morphology, and clinical characteristics in predicting major adverse cardiac events during and after native coronary balloon angioplasty. Am J Cardiol 1993; 72: 14-20

12. Rose AD, Detre KM, Alderman ELL, Stadius M, Sopko G, and the Bypass Angioplasty Revascularization Investigation Study Group. How reliable is the assessment of coronary angiography? (abstract no 3515) Circ (Suppl) 1993; 88(4 part 2): I-653

13. Myler RK, Shaw RE, Stertzer SH, Hecht HS, Ryan C, Rosenblum J, Cumberland DC, Murphy MC, Hansell HN, Hidalgo B. Lesion morphology and coronary angioplasty: current experience and analysis. JACC 1992; 19: 1641-52

14. Mabin AT, Holmes DR, Smith HC, Vlietstra RE, Bove AA, Reeder GS, Chesebro JH, Bresnahan JF, Orszulak TA. Intracoronary thrombus: role in coronary occlusion complicating percutaneous transluminal coronary angioplasty. JACC 1985; 5: $198-202$

Address for correspondence: P.W. Serruys, Department of Interventional Cardiology, Erasmus University, PO BOX 1738, 3000 DR Rotterdam, The Netherlands 